\title{
Матричная тепловизионная система, интегрированная в многоканальный автоматизированный биомедицинский комплекс
}

\author{
Б.Г. Вайнер ${ }^{1,2)}$, А.Е. Настовьяк ${ }^{1)}$ \\ ${ }^{1}$ Институт физики полупроводников им. А.В. Ржанова СО РАН, \\ Новосибирск, 630090, пр-т Ак. Лаврентьева, 13 \\ ${ }^{2}$ Новосибирский государственный университет, Новосибирск, 630090, ул. Пирогова, 2 \\ тел: +7 (383) 330-7781, эл. почта: $\underline{\text { BGV@isp.nsc.ru }}$
}

DOI 10.34077/RCSP2019-138

При разработке новых направлений в создании тепловизионных систем, ориентированных на применение в разнообразных научных исследованиях, следует предусматривать не только техническое совершенствование самих тепловизионных камер и детекторов ИК излучения, но также реализовывать возможность максимального использования современных аппаратных и программных средств автоматизации эксперимента. Интегрирование тепловизионного прибора в автоматизированный измерительный комплекс особенно значимо и актуально сегодня, поскольку при традиционном подходе даже самые совершенные матричные тепловизоры вплоть до настоящего времени привлекаются к экспериментальной работе преимущественно лишь в качестве инструмента, функционирующего независимо и изолированно от от других средств измерений. Это зачастую ограничивает производительность исследований, снижает достоверность и информативность полученных результатов.

В настоящей работе представлены результаты, отражающие преимущества современного подхода в области инфракрасной динамической термографии. Тепловизионная камера применена здесь для биомедицинских исследований синхронно с другими диагностическими устройствами. Это позволило полноценно регистрировать и анализировать характеристики биофизические прочессов в организме не в отрыве их друг от друга, а совместно, что увеличило достоверность извлекаемых биоданных.

Основным узлом, обеспечивающим автоматизацию эксперимента, является сервер, основные принципы работы которого нами изложены в [1]. Включенные в измерительный комплекс устройства объединены в единую

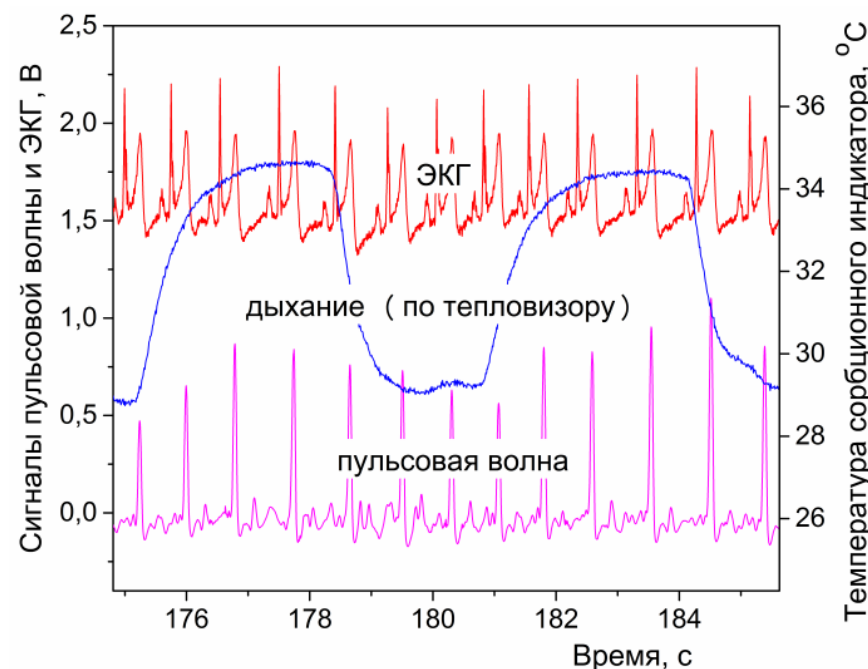

Рис. 1. Результат синхронного измерения нескольких биофизических характеристик организма человека с использованием тепловизионного информационного канала данных.

локальную сеть с помощью Ethernet маршрутизатора. Одним из основных блоков, позволяющих конвертировать аналоговые сигналы, поступающие с биодатчиков, в цифровые, служит измерительная система MP100A-CE (Biopac Systems Inc., Santa Barbara, California, USA).

На рис. 1 показан пример синхронного применения устройств для измерения электрокардиограммы и пульсовой волны в лучевой артерии (область запястья) с интегрированным в эту систему матричным тепловизором ТКВр-ИФП (ИФП СО РАН, Новосибирск, Россия). С помощью тепловизионной камеры здесь измеряются не только динамические изменения температуры конечностей (на графике не показаны), но также профиль дыхания. Последний прецизионно определяется по температуре сорбционного индикатора тепловизионным методом SEIRT, описанным в [2]. Помимо упомянутых характеристик, в данной живой системе анализируются также другие, расширенный перечень которых приведен в [3].

Работа выполнена при финансовой поддержке РФФИ и Правительства Новосибирской области, грант № 18-44-540040.

\section{Лuтература}

[1] А.Е. Настовьяк, Б.Г. Вайнер // Научный альманах. 2016. № 10-3. С. 391-397.

[2] B.G. Vainer // Ann. Biomed. Eng. 2018. Vol. 46. P. 960-971.

[3] B.G. Vainer // In: APEIE-2018, Proc. // Novosibirsk: NSTU, IEEE, 2018. V.1, Part 2. P. 334-338. 